\title{
Entropy Generation Analysis for Various Cross-sectional Ducts in Fully Developed Laminar Convection with Constant Wall Heat Flux
}

\author{
Haghgooyan, M. S. ${ }^{\dagger}, *$ and Aghanajafi, C.** \\ *Department of Mechanical Engineering, Islamic Azad University-South branch, Tehran, Iran \\ **Department of Mechanical Engineering, K.N. Toosi University of Technology, Tehran, Iran \\ (Received 7 December 2013; Received in revised form 3 March 2014; accepted 19 March 2014)
}

\begin{abstract}
This study focuses on analysis and comparison of entropy generation in various cross-sectional ducts along with fully developed laminar flow and constant uniform wall heat flux. The obtained results were compared in ducts with circular, semicircular, and rectangular with semicircular ends, equilateral triangular, and square and symmetrical hexagonal cross-sectional areas. These results were separately studied for aspect ratio of different rectangular shapes. Characteristics of fluid were considered at average temperature between outlet and inlet ducts. Results showed that factors such as Reynolds number, cross section, hydraulic diameter, heat flux and aspect ratio were effective on entropy generation, and these effects are more evident than heat flux and occur more in high heat fluxes. Considering the performed comparisons, it seems that semicircular and circular cross section generates less entropy than other cross sections.
\end{abstract}

Key words: Entropy Generation, Variety, Cross-sectional, Laminar, Flow, Heat Flux

\section{Introduction}

Analysis of heat transfer and entropy generation and also study of the second law of thermodynamics in terms of irreversibility in heat transfer processes give us an important and broad view for selecting dimensions and shapes of all kinds of heat exchanger. Exergy analysis is important and effective for selecting a duct for all engineering applications. Different factors play a role in entropy generation and irreversibility of a heat transfer in duct such as type of cross section of the duct, fluid friction, type of fluid flow, dimensions of duct and heat flux. The use of all kinds of fin and metal foams around duct can be effective on the phenomenon of heat transfer.

Bejan [1] conducted many studies on irreversibility and entropy generation in heat exchangers. He obtained good results on minimization of entropy generation in viscose fluids and in dimensional level of duct. Ahmet and Sahin [2] found that high Reynolds number would lead to friction irreversibility in all kinds of circular, triangular and sinus ducts and other ducts. The most optimal cross section of the duct for passage of fluid in laminar flow with constant temperature of the duct wall and turbulent flow with constant wall heat flux is spherical. Ou and Cheng [3] conducted research on the effect of viscosity on heat transfer of pipe flow with uniform wall temperature. Nug and Mukherjee [4] studied optimization of the second law of thermodynamics for transferring convection heat through a duct

\footnotetext{
${ }^{\dagger}$ To whom correspondence should be addressed.

E-mail: st ms haghgooyan@azad.ac.ir

This is an Open-Access article distributed under the terms of the Creative Commons Attribution Non-Commercial License (http://creativecommons.org/licenses/bync/3.0) which permits unrestricted non-commercial use, distribution, and reproduction in any medium, provided the original work is properly cited.
}

along with constant heat flux boundary. Heat transfer and pressure drop in different shapes of ducts was also studied by Shah and London [5]. Oztop [6] studied entropy generation in semicircular and rectangular with semicircular ends duct. These studies have been conducted in two states of constant wall temperature and constant heat flux in wall. Flahat [7] studied the second law of thermodynamics in annular sector and circular segment ducts in fully developed laminar flow and constant heat flux boundary. He found that when Reynolds number increased, entropy generation would drop and when heat flux in wall of the duct increased in a constant Reynolds number, the entropy generation would decrease. He looked at the effect of segment angle and heat flux and found that a circular segment duct was more optimal than a circular duct. Jaukowski and Todda [8] studied optimization of entropy generation in internal flows by comparing shapes of cross section of the duct. They noticed that circular cross section led to minimum entropy generation. Sompop and Jarangthamm [9] studied analysis of the entropy generation in fully developed laminar flow in a hexagonal duct along with constant heat flux in wall. They compared the obtained results with a rectangular duct, and showed that the characteristics of a fluid had considerable effect on entropy generation; and when aspect ratio increased, the dimensionless entropy generation became small. The reason is that heat transfer rate is reduced with increase of aspect ratio in a constant heat flux. Vandadi and Aghanajafi [10] considered entropy generation analysis for micro scale forced convection in thermal entrance region. In this study the effect of Knudsen number and Brinkman number on the entropy generation rate and Bejan number in different axial location is presented. Aghanajafi and Mansourizadeh [11] studied velocity and thermal boundary layer and 
entropy generation near the periodically oscillating flat plate.They found computational fluid dynamics to solve the problem of vibrating plate in order to fine velocity, temperature and entropy distribution of each particle of fluid. Langeroudi and Aghanajafi $[12,13]$ strove for important thermal contact (enhanced-heat transfer) and reduced pump power loss in order to improve the thermodynamic efficiency of the heat exchanger. Good heat exchanger design means, ultimately, efficient thermodynamic performance, that is, the least generation of entropy or least destruction of useful work in an engineering system is directly proportional to the rate of entropy generation. Satapathy [14] optimized the geometry of a coiled heat exchanger tube using the minimization of entropy generation method. The author pointed out that the optimum value of diameter ratio decreased with increasing Dean or Reynolds number. Hong and Bergles [15] obtained the thermal entry length solutions for semicircular duct for both constant heat flux and constant temperature boundary conditions for Newtonian fluid. Haddad et al. [16] investigated the entropy generation in a laminar forced convection in the entrance region of a concentric annulus using various thermal boundary conditions.

All of the studies investigated the subject and parameter which are effective in analysis of the entropy generation, but a question is raised here: what kind of cross section with what dimensions of duct are better for passage of fluid along with fully developed laminar flow and constant heat flux in wall of duct?

In summary, there is no comprehensive study in this field and general study of parameters effective on the entropy generation of different cross sections. In addition, there are contradictions in the mentioned studies in selection of the best shape of cross section of duct for transferring heat and the entropy generation in engineering applications which are mentioned later.

We investigated and compared all cross sections of ducts and effect of aspect ratio in rectangle, Reynolds numbers and heat fluxes by reviewing more than twenty different papers in this field and comparing circular, equilateral triangular, symmetrical hexagonal, square, semicircular and rectangular with semicircular ends sections with each other.

\section{Entropy Generation Analysis}

In this section, entropy generation is studied and formulated. All formulas of entropy generation result from general relation of energy balance in which characteristics of fluid along duct are considered equal. Control volume exposed to constant heat flux for all ducts is shown in Fig. 1, where $\dot{m}$ is mass flow rate.

Energy balance for $\mathrm{dx}$ length of control volume is as follows:

$$
\mathrm{dQ}=\ddot{\mathrm{q}} \mathrm{Pdx}=\overline{\mathrm{h}} \mathrm{Pdx} \Delta \mathrm{T}=\dot{\mathrm{m}} \mathrm{c}_{p} \mathrm{dT}
$$

where $\mathrm{h}$ and $\mathrm{P}$ are heat transfer coefficient and diameter of the sections. $\mathrm{Cp}$ is fluid specific heat and $\Delta \mathrm{T}=\left(\mathrm{T}_{w}-\mathrm{T}\right)$ is difference between fluid temperature and temperature of duct wall. A displacement and integration in Equation (1) yields Equation (2):

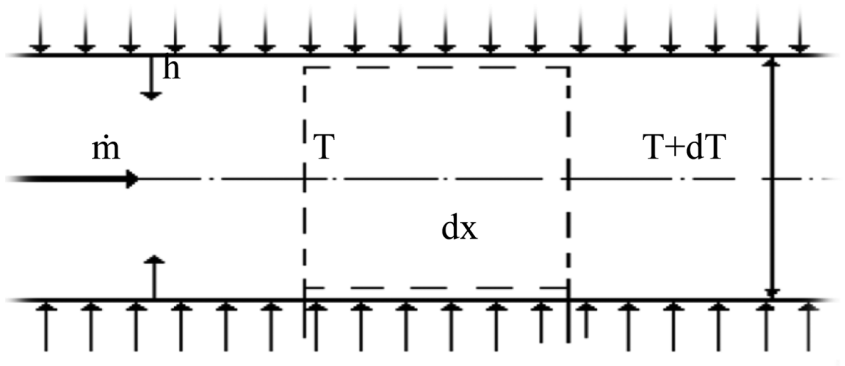

Fig. 1. Internal flow with constant heat flux.

$$
\mathrm{T}_{x}=\mathrm{T}_{i}+\frac{\ddot{\mathrm{P}}}{\dot{\mathrm{mc}}_{p}} \mathrm{x}
$$

Equation (2) can be rewritten with dimensionless Stanton number $\mathrm{St}=\mathrm{h} /$ puc $_{p}$ where $\rho$ is fluid density and $\mathrm{u}$ is its average velocity.

$$
\mathrm{T}_{x}=\mathrm{T}_{i}+\frac{4 \mathrm{St} \Delta \mathrm{T}}{\mathrm{D}_{h}} \mathrm{x}
$$

The expression $\mathrm{D}_{h}$ in Equation (3) indicates hydraulic diameter of duct.

The entropy generation for this control volume is equal to:

$$
\mathrm{d} \dot{s}_{g e n}=\dot{\mathrm{m} d s}-\frac{\mathrm{d} \dot{\mathrm{Q}}}{\mathrm{T}+\Delta \mathrm{T}}
$$

where $\mathrm{d}_{s}$ for an incompressible fluid, is as follows:

$$
\mathrm{ds}=\mathrm{c}_{P} \mathrm{dT} / \mathrm{T}-\frac{\mathrm{dP}}{\rho \mathrm{T}}
$$

By substituting Equation (5) in Equation (4) and also using Equation (3) therein, after integration, we have:

$$
\frac{\mathrm{ds}_{g e n}}{\mathrm{dx}}=\dot{\mathrm{m}} \mathrm{c}_{p} \frac{\mathrm{dT}}{\mathrm{dx}} \frac{\Delta \mathrm{T}}{\mathrm{T}(\mathrm{T}+\Delta \mathrm{T})}+\frac{\dot{\mathrm{m}}}{\rho \mathrm{T}}\left(-\frac{\mathrm{dP}}{\mathrm{dx}}\right)
$$

The expression "pressure gradient "in Equation (6) can be mentioned as follows:

$$
-\frac{d P}{d x}=\frac{f \rho \bar{U}^{2}}{2 D_{h}}
$$

where $\mathrm{f}$ is friction factor.

At the end, by substituting Equation (7) in Equation (6) and simplification, we have:

$$
\dot{\mathrm{S}}_{g e n}=\dot{\mathrm{m}} \mathrm{c}_{p} \ln \left[\frac{\left(\mathrm{T}_{i}+\frac{\ddot{\mathrm{q}} \mathrm{D}_{h}}{\mathrm{~K}_{\mathrm{Nu}}}\right) \mathrm{T}_{o}}{\mathrm{~T}_{i}\left(\mathrm{~T}_{i}+\frac{\ddot{\mathrm{q}} \mathrm{D}_{h}}{\mathrm{~K} \overline{\mathrm{Nu}}_{c p}}+\frac{\ddot{\mathrm{q} P L}}{\dot{\mathrm{mc}}_{p}}\right)}\right]+\frac{\mathrm{f} \dot{\mathrm{m}} \overline{\mathrm{U}}^{2} \mathrm{~L}}{2 \mathrm{D}_{h}}\left(\frac{\ln \frac{\mathrm{T}_{o}}{\mathrm{~T}_{i}}}{\mathrm{~T}_{o}-\mathrm{T}_{i}}\right)
$$

where $\mathrm{Nu}=\mathrm{hDh} / \mathrm{k}$ is Nusselt number.

The expression of Nusselt number and number of fRe has been empirically studied by Shah and London [5] and results for different shapes are found in Table 1 where $\mathrm{Re}=\rho \mathrm{uD}_{h} / \mu$ is Reynolds number. The expression $\mu$ is fluid viscosity. 
Table 1. Values of fRe and Nu for constant heat flux boundary conditions

\begin{tabular}{lcc}
\multicolumn{2}{c}{ in various cross sections } & \\
\hline \hline Cross sectional & $\mathrm{Nu}$ & $\mathrm{f} \mathrm{Re} / 4$ \\
\hline Circular & 4.364 & 16 \\
Square & 3.608 & 14.227 \\
Semicircular & 6.724 & 15.823 \\
Hexagonal & 4.002 & 15.054 \\
Triangular & 3.111 & 13.333 \\
Rectangular with semicircular & 4.364 & 17.03 \\
$\quad$ ends and $\mathrm{B}=1 / 2$ & 4.123 & 15.548 \\
Rectangular $\mathrm{B}=1 / 2$ & 4.79 & 17.25 \\
Rectangular $\mathrm{B}=1 / 3$ & 5.331 & 18.23 \\
Rectangular $\mathrm{B}=1 / 4$ & 6.49 & 20.585 \\
Rectangular $\mathrm{B}=1 / 8$ & &
\end{tabular}

The expression "entropy generation" can be defined dimensionless for comparison which is as follows:

$$
\Psi=\frac{\dot{\mathrm{S}}_{G E N}}{\dot{\mathrm{Q}} / \mathrm{T}_{o}-\mathrm{T}_{i}}
$$

The dimensionless total entropy generation based on the flow stream heat capacity rate $\left(\dot{\mathrm{m}} / \mathrm{c}_{p}\right)$ is defined as:

$$
\Psi=\ln \left[\frac{\left(\operatorname{Re}+\tau \eta_{1}\right)(1+\tau)}{\left(\operatorname{Re}+\tau \operatorname{Re}+\tau \eta_{1}\right)}\right]+\eta_{2} \operatorname{Re}^{2} \ln \left(\frac{\operatorname{Re}+\tau \eta_{1}}{\operatorname{Re}}\right)
$$

In this equation $\eta_{1}$ and $\eta_{2}$ are:

$$
\begin{aligned}
& \eta_{1}=4 \mathrm{Nu} \lambda / \operatorname{Pr} \\
& \eta_{2}=\mu^{3} \mathrm{f} \operatorname{Re} / 8 \rho^{2} \mathrm{D}_{h}^{3} \mathrm{q}
\end{aligned}
$$

In these equations some parameters can be made dimensionless as follows:

$$
\begin{aligned}
& \mathrm{St}=\frac{\mathrm{h}}{\rho \mathrm{UC}_{p}}=\frac{\mathrm{Nu}}{\mathrm{RePr}} \\
& \tau=\frac{\mathrm{T}_{w}-\mathrm{T}}{\mathrm{T}_{o}} \\
& \lambda=\frac{\mathrm{L}}{\mathrm{D}_{h}}
\end{aligned}
$$

In Fig. 2, all of the studied cross sections along with necessary parameters are shown.

For fully developed flow and fully wet section, hydraulic diameter is obtained as follows:

a)

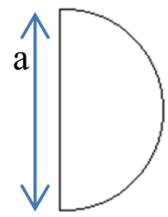

b)

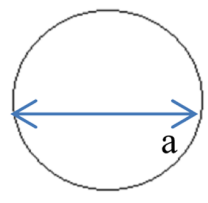

c)

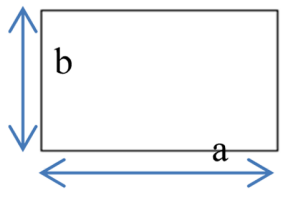

Table 2. Definition of hydraulic diameter in various cross-sections

\begin{tabular}{lc}
\hline \hline Circular & $\mathrm{A}$ \\
Triangular & $\sqrt{3} / 3 \mathrm{a}$ \\
Semicircular & $\Pi d / 2+\Pi$ \\
Rectangular & $(\beta / \beta+1)^{\mathrm{x}} 2 \mathrm{a}$ \\
Rectangular with semicircular ends $\beta=1 / 2$ & $(4+\Pi / 2+\Pi)^{\mathrm{x}} \mathrm{a}$ \\
Hexagonal & $\sqrt{3} \mathrm{x}_{\mathrm{a}}$ \\
\hline
\end{tabular}

$$
\begin{aligned}
& \mathrm{D}_{h}=\frac{4 \mathrm{~A}_{c}}{\mathrm{P}} \\
& \beta=\mathrm{b} / \mathrm{a}
\end{aligned}
$$

This is summarized for different shapes in Table 2 .

\section{Results and Discussion}

This section compares dimensionless entropy generation through different ducts with circular, semicircular, square, symmetrical hexagonal, equilateral triangle and rectangular with semicircular ends with aspect ratio of $1 / 2$.

The passing fluid is in a water duct and its flow has been considered as fully developed laminar. To reach laminar flow, we have assumed hydraulic diameter and mass flow such that the Reynolds number is between $0<\operatorname{Re}<3000$. All of the analyzed ducts are exposed to different fluxes of 1000, 2500, 2000, 1500 and $3000 \mathrm{~W} / \mathrm{m}^{2}$. All characteristics used for water fluid are considered constant and equal along the duct and these characteristics of fluid are at average temperature between outlet and inlet of the fluid. These characteristics are observed in Table 3. Average temperature has been obtained such that we first inserted $\mathrm{Cp}$ for water at inlet temperature in calculation and calculated average temperature after obtaining outlet temperature and putting new $\mathrm{Cp}$ based on it. We performed this work in some stages until changes of outlet temperature could be lower than $1 \%$. Other hypotheses of the duct are found in Table 3.

Comparisons of dimensionless entropy generation with Reynolds number and cross section have been made for all sections with equal

Table 3. Parameter values used in the analysis

\begin{tabular}{cc}
\hline \hline $\mathrm{L}$ & $10 \mathrm{~m}$ \\
$\mathrm{~T}_{i}$ & $298 \mathrm{k}$ \\
$\dot{\mathrm{m}}$ & $0.05 \mathrm{~m}^{3} / \mathrm{s}$ \\
$\mathrm{Cp}$ & $4182 \mathrm{~J} / \mathrm{Kg} \cdot \mathrm{k}$ \\
$\mu$ & $9.93^{*} 10^{-4}$ \\
\hline
\end{tabular}

d)

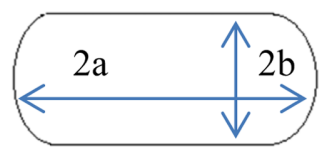

e)

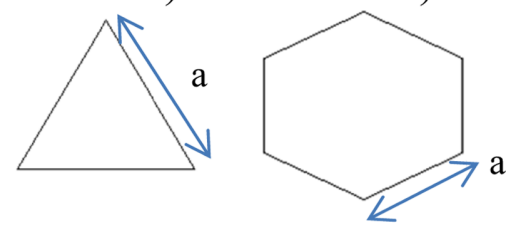

Fig. 2. Cross-sectionals of (a) semicircular, (b) circle, (c) rectangular, (d) rectangular with semicircular ends, (e) equilateral triangular, (f) symmetrical hexagonal. 

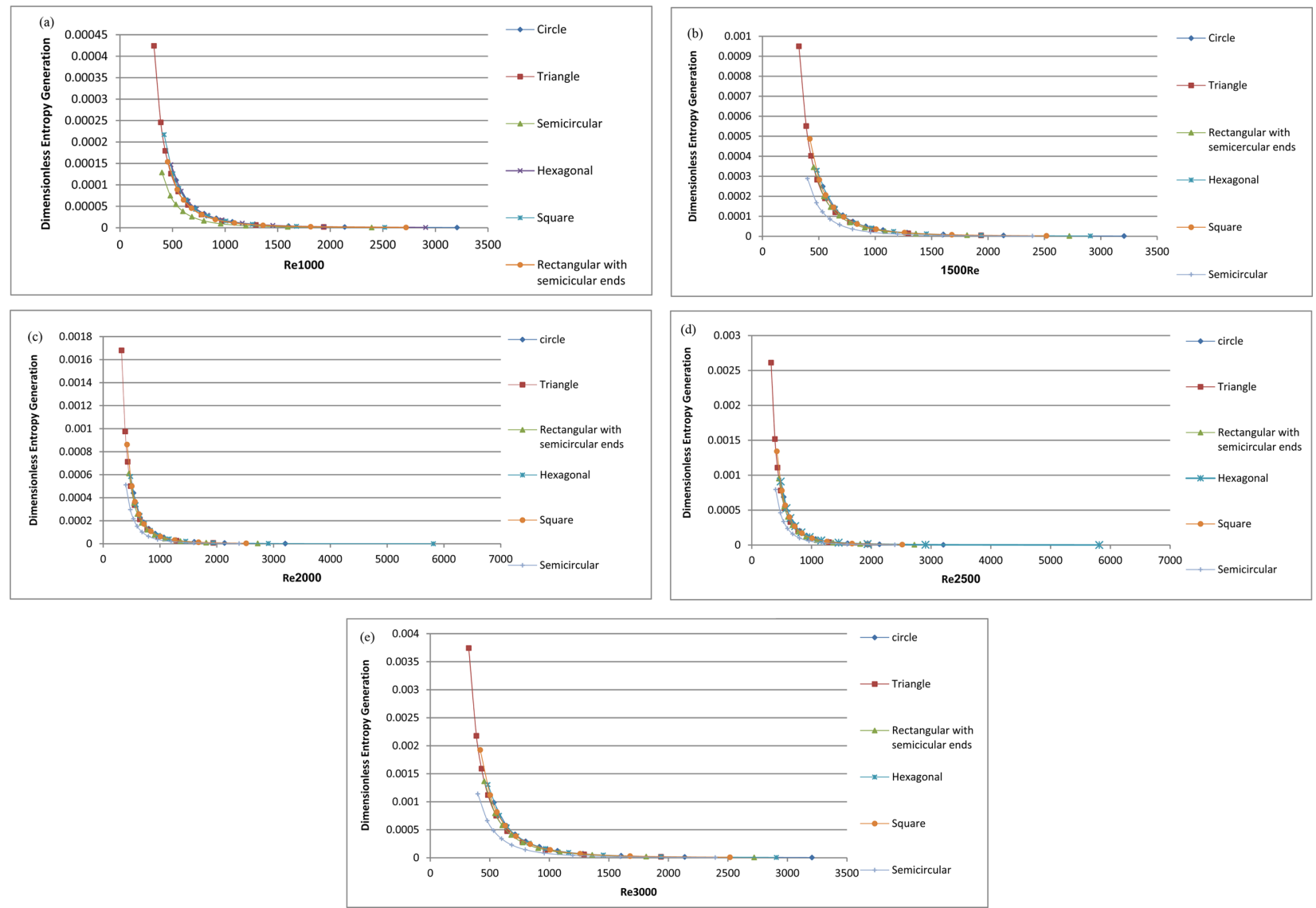

Fig. 3. Comparing dimensionless entropy with Reynolds in different fluxes. (a) 1000, (b) 1500, (c) 2000, (d) 2500, (e) $3000 \mathrm{~W} / \mathrm{m}^{2}$.
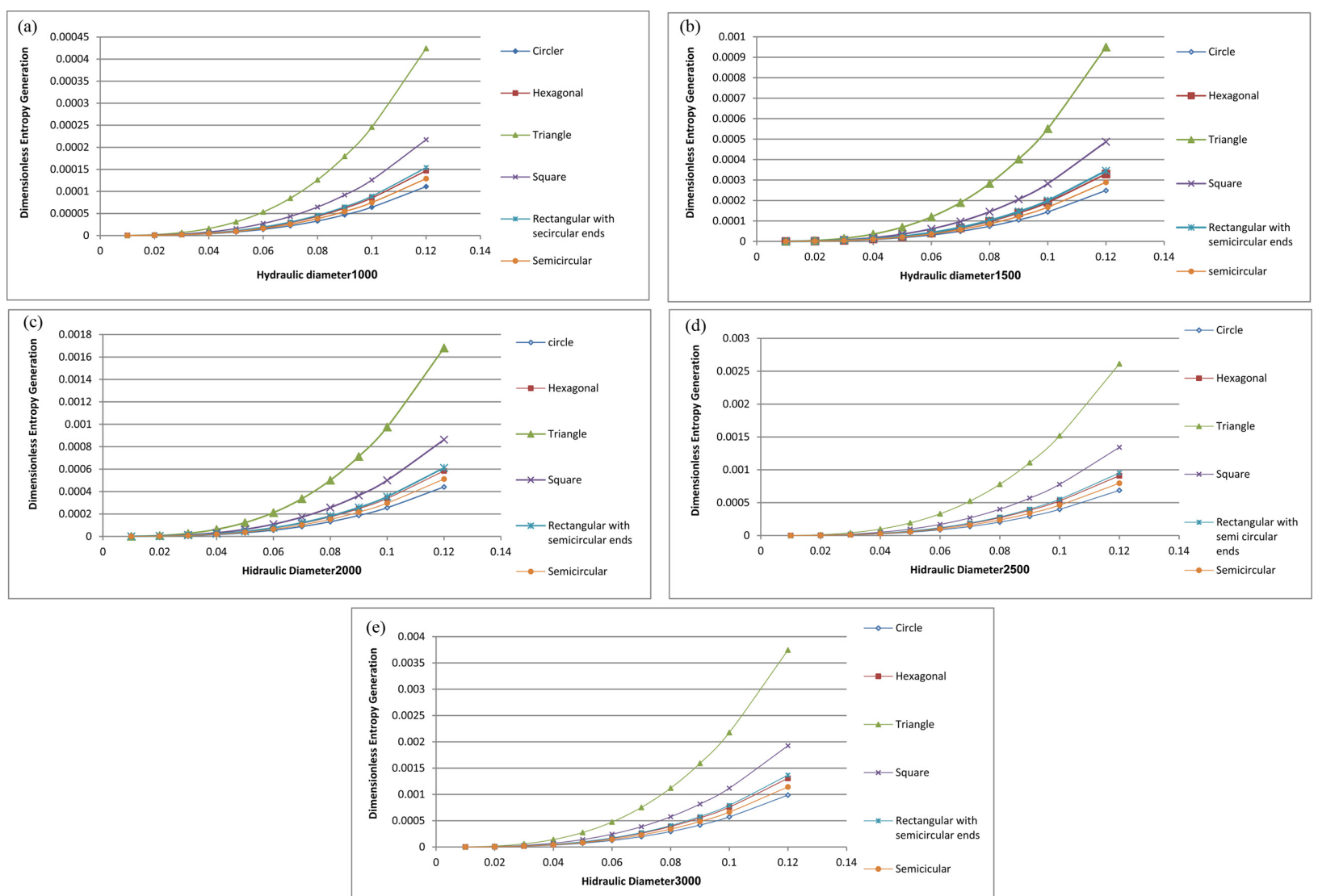

Fig. 4. Comparing dimensionless entropy generation with hydraulic diameter in different fluxes. (a) 1000, (b) 1500, (c) $2000, d), 2500$, (e) 3000. 

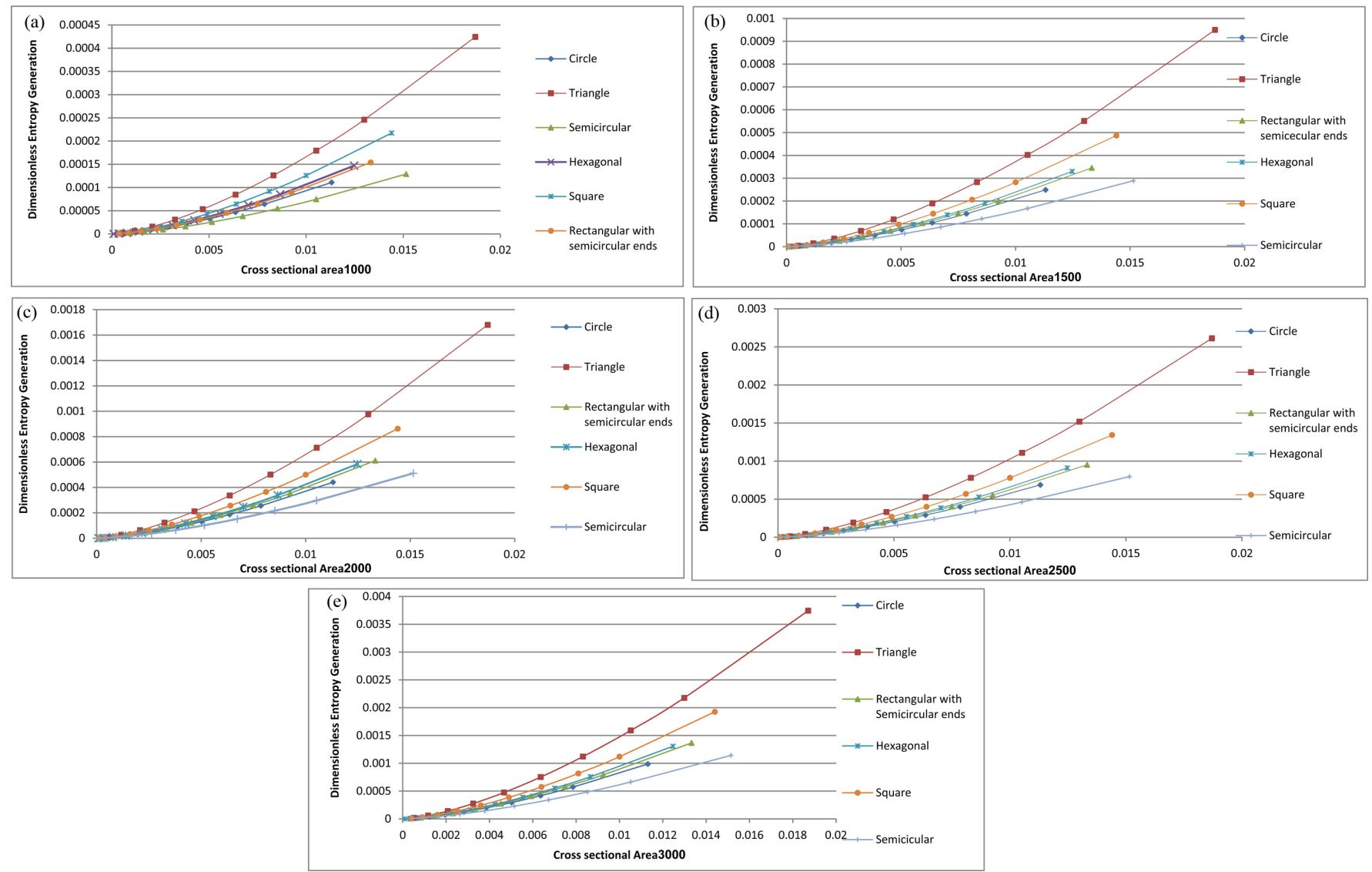

Fig. 5. Comparing dimensionless entropy generation with cross section in different heat fluxes. (a) 1000, (b) 1500, (c) $2000, d$ ), 2500, (e) 3000.
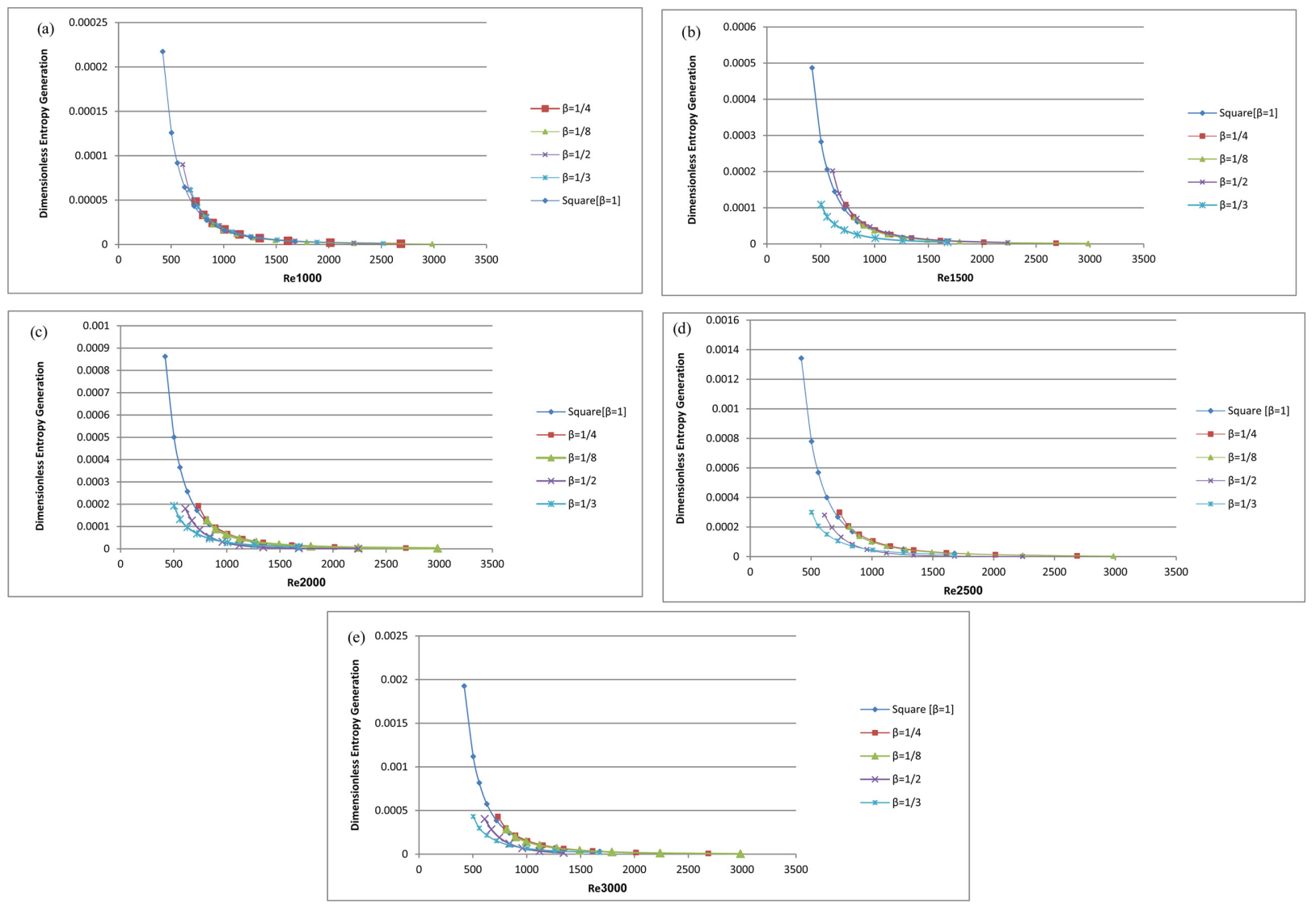

Fig. 6. Comparing dimensionless entropy generation with Reynolds for rectangular aspect ratio in different heat fluxes. (a) 1000, (b) 1500 , (c) 2000, (d) 2500, (e) 3000 .

Korean Chem. Eng. Res., Vol. 52, No. 3, June, 2014 
hydraulic diameter. As many various hydraulic diameters have been assumed, then the hydraulic diameters are shared between all crosssectionals. Based on this calculation, the hydraulic diameter was first assumed for each cross section and then Reynolds number was calculated using it. These comparisons were made for different shapes in variables such as Reynolds number, hydraulic diameter and cross section. Results of calculation in different Reynolds number for various heat flux are mentioned in Figs. 3(a d) and (e).

As observed above, increase of Reynolds reduces entropy generation so that the highest slope of the diagram relating to Reynolds is between 0 and 1000 .

Considering the shown diagrams, it is specified that increase of heat flux decreases descending trend of dimensionless entropy generation and also increases dimensionless entropy generation. Results show that the lowest dimensionless entropy generation is related to a semicircle in a given Reynolds number and the highest dimensionless entropy generation is also related to square and equilateral triangle. Results of calculation in different hydraulic diameters and exposed to different constant heat fluxes are found in Figs. 4(a d) and (e).

These comparisons were made for different cross sections. Results show that the lowest dimensionless entropy generation relates to circular and semicircular and these changes are more evident in higher heat fluxes. After circular, the lowest dimensionless entropy generation relates to symmetrical hexagonal, rectangular with semicircular ends, square and triangular shapes. It seems that the reason is high friction between wall and fluid, and increase of hydraulic diameter as well as cross section of the duct expands the lateral area of the duct. As a result, the contact surface between fluid and wall of duct increases, which is the reason for increase of dimensionless entropy generation. As observed above, an increase of heat flux enhances ascending trend of dimensionless entropy generation in a given hydraulic diameter and for different cross sectional areas, and this increase is higher for triangle and square. To show dimensional effect of cross section, a comparison was made between different heat fluxes for circular, semicircular, triangular, symmetrical hexagonal and rectangular with semicircular ends cross sections and dimensionless entropy generation.

Results for comparing cross section and dimensionless entropy generation are shown for 1000, 1500, 2000, 2500 and $3000 \mathrm{w} / \mathrm{m}^{2}$ heat fluxes in Figs. 5(a e), respectively.

Results for cross sectional area are similar to results obtained by comparison with hydraulic diameter. With increase of heat flux, inlet and outlet temperature difference of fluid increases, which is the reason for increase of dimensionless entropy generation. Fig. 4-3 shows that increase of dimensions of cross sectional area enhances dimensionless entropy generation, and the highest increase relates to triangular shape and the lowest increase relates to semicircle. Studies show that hexagonal and circular cross sectional areas are regarded
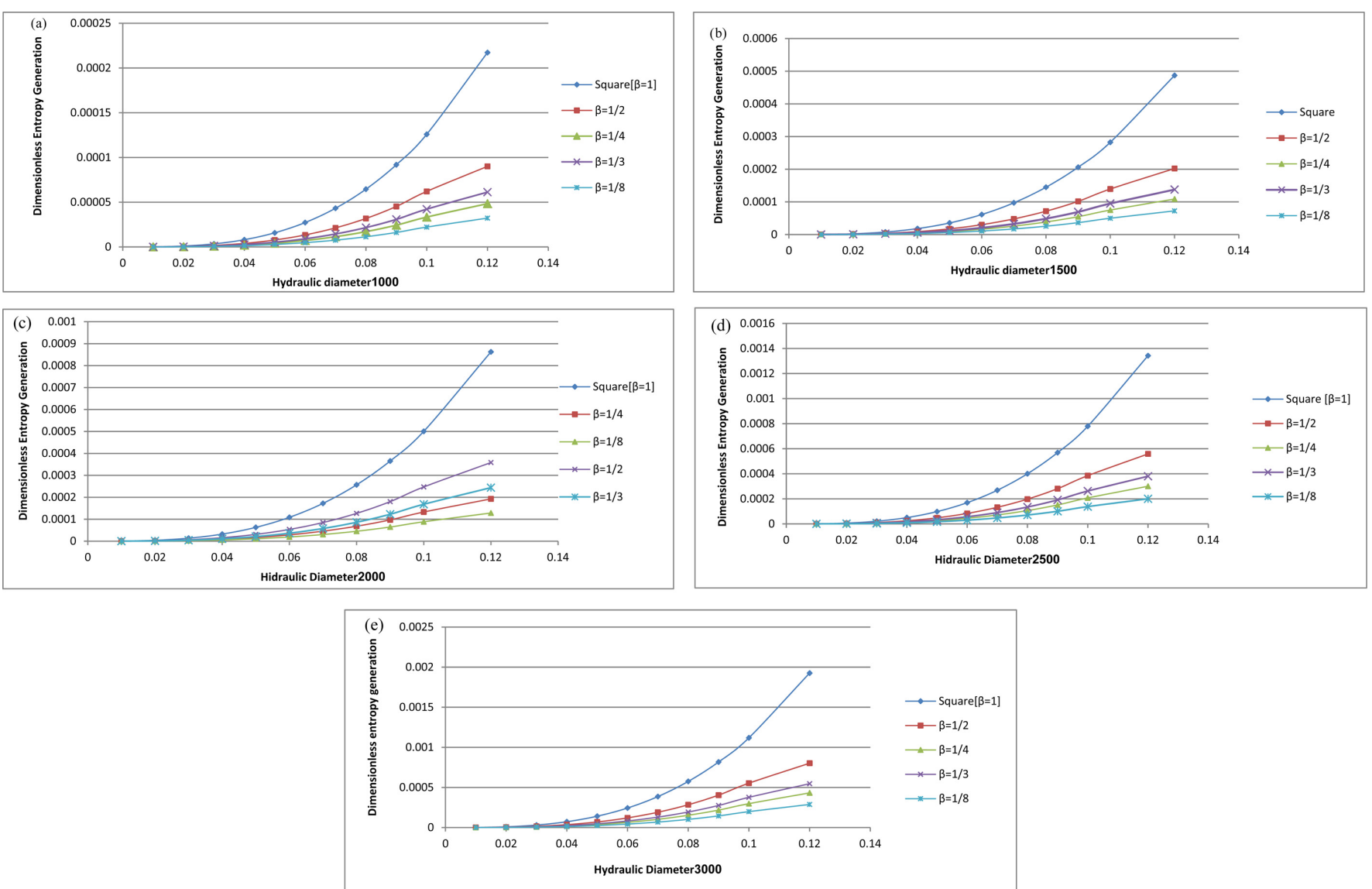

Fig. 7. Comparing dimensionless entropy generation with hydraulic diameter for rectangular aspect ratio in different heat fluxes. (a) 1000 , (b) 1500 , (c) 2000, (d) 2500, (e) 3000. 

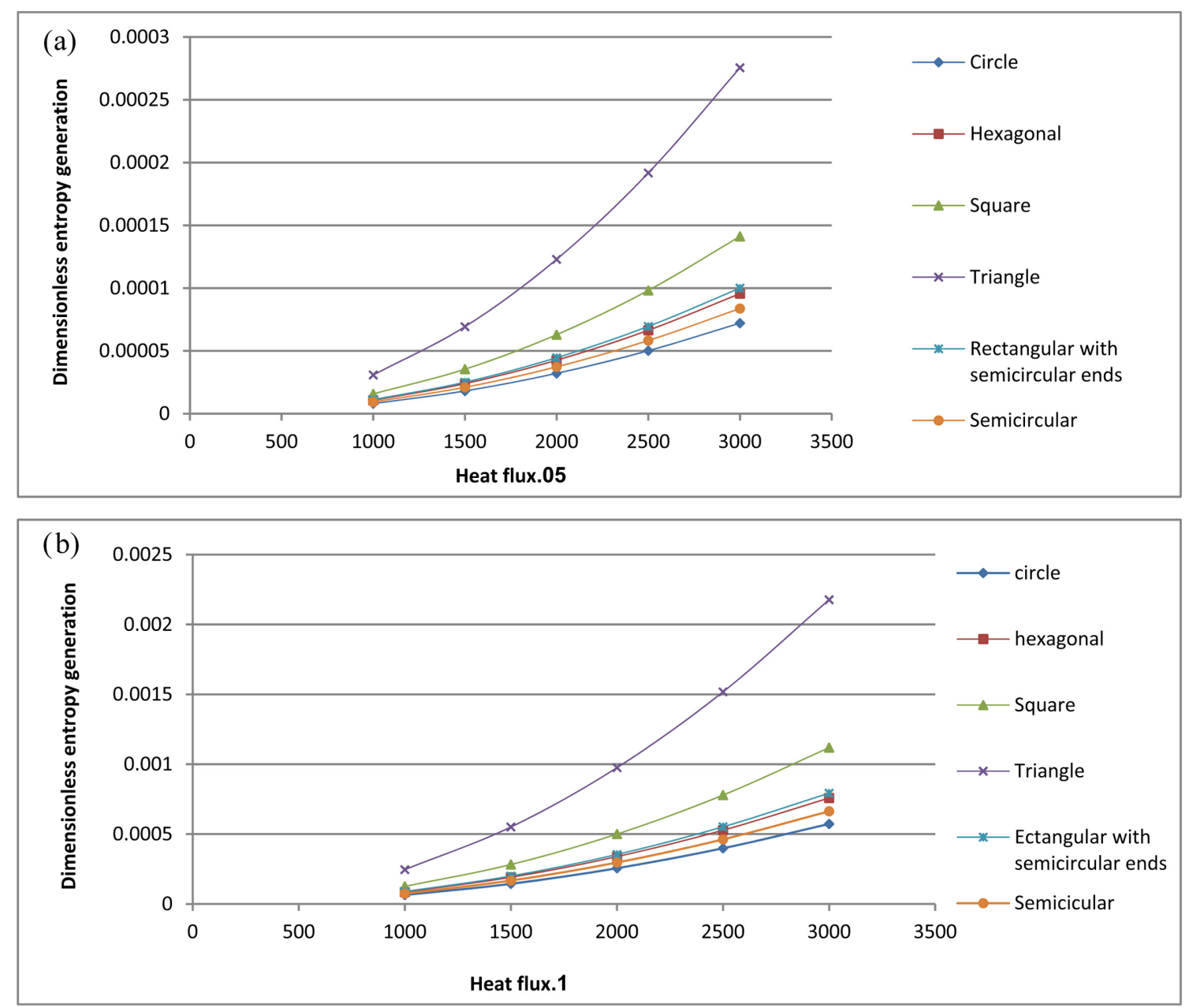

Fig. 8. Comparing dimensionless entropy generation with heat flux in different cross sections for (a) Dh=.05, (b) Dh=.1.

as the cross sectional areas which have the lowest entropy generation after semicircle. To study the effect of aspect ratio, comparison of dimensionless entropy generation with rectangular aspect ratio was used. In Figs. 6(a e), dimensionless entropy generation has been compared with Reynolds number in heat fluxes of 1000, 1500, 2000, 2500 and $3000 \mathrm{w} / \mathrm{m}^{2}$, respectively. Results for aspect ratio of $1,1 / 2$, $1 / 3,1 / 4$ and $1 / 8$ of rectangle were compared with each other.

It is observed that the lowest entropy generation relates to aspect ratio of 1,1/2,1/3,1/4 and 1/8 and these changes occur more in high heat fluxes. In addition, with increase of heat flux the slope of the diagram will be sharp, which indicates important effect of heat flux.

In Figs. 7(a e), dimensionless entropy generation was studied in different hydraulic diameter for different aspect ratio of rectangle. The obtained results are shown for heat fluxes of 1000, 1500, 2000, 2500 and $3000 \mathrm{w} / \mathrm{m}^{2}$, respectively. As observed above, increase of hydraulic diameter enhances dimensionless entropy generation which is also caused by high heat flux. The highest dimensionless entropy generation relates to square, and the lowest entropy relates to aspect ratio of 1/8. Results show that decrease of aspect ratio reduces dimensionless entropy generation in a constant hydraulic diameter.

Finally, a comparison was made between dimensionless entropy generation and heat flux in two hydraulic diameters to show the effect of heat flux. The obtained results for hydraulic diameter of 0.05 are shown in Fig. 8(a), and for hydraulic diameter of 0.1 in Fig. 8(b).

Results show that in a constant heat flux, the highest dimensionless entropy generation relates to triangle and the lowest dimensionless entropy generation relates to circle. By increase of heat flux in a constant hydraulic diameter, dimensionless entropy generation increases, which is in line with the results obtained in the above figures.

\section{Conclusions}

We studied the dimensionless entropy generation in ducts with circular, equilateral triangular, symmetrical hexagonal, square, semicircular and rectangular with semicircular ends sections and aspect ratio of $1 / 2$ along with fully developed laminar flow and under constant heat flux in wall of the duct. Results show that:

By increase of the heat flux, the entropy generation increases in all shapes, and this increase for triangle is higher than that for other shapes and the lowest increase is observed in circular shape.

By increase of the cross-sectional area and hydraulic diameter, entropy generation will increase and the lowest increase relates to cir- 
cle and semicircle. By increase of Reynolds number from 0 to 3000, entropy generation considerably decreases. At low Reynolds numbers, the entropy generation descending trend is higher, and also the lowest entropy generation relates to a semicircle in a given Reynolds number.

In a constant hydraulic diameter for different rectangle aspect ratio, with increases of the aspect ratio, the entropy generation will increase. At a constant Reynolds number, the aspect ratio of $1 / 3$ has the lowest entropy generation, which becomes more evident at high heat fluxes.

Considering the performed comparisons, it seems that semicircular and circular cross sectional areas has the lowest entropy generation compared with other cross-sectional areas.

\section{Nomenclatures}

a,b : duct sides [m]

cp : specific heat $[\mathrm{J} / \mathrm{kg} \mathrm{K}]$

$\mathrm{Dh} \quad$ : hydraulic diameter, $\mathrm{m} \mathrm{f}$ friction factor or Darcy friction factor

$\mathrm{h} \quad$ : heat transfer coefficient $\left[\mathrm{W} / \mathrm{m}^{2} \mathrm{~K}\right]$

$\mathrm{k} \quad$ : thermal conductivity [W/m K]

L : duct length [m]

m : mass flow rate $[\mathrm{kg} / \mathrm{s}]$

$\mathrm{Nu} \quad$ : Nusselt number

$\mathrm{P} \quad$ : pressure $[\mathrm{Pa}]$

$\mathrm{p} \quad$ : perimeter $[\mathrm{m}]$

$\dot{\mathrm{q}}^{\prime \prime} \quad$ : heat flux $\left[\mathrm{W} / \mathrm{m}^{2}\right]$

$\dot{\mathrm{Q}} \quad$ : heat rate $[\mathrm{W}]$

Re : Reynolds number

$\mathrm{S} \quad$ : specific entropy $[\mathrm{J} / \mathrm{kg} . \mathrm{K}]$

$\dot{\mathrm{S}} \quad$ : entropy rate $[\mathrm{W} / \mathrm{K}]$

St : Stanton number

$\mathrm{T} \quad$ : fluid temperature $[\mathrm{K}]$

$\mathrm{U} \quad$ : fluid velocity $[\mathrm{m} / \mathrm{s}]$

\section{Greek Letters}

dT : wall-bulk fluid temperature difference $\left[\mathrm{T}_{w}-\mathrm{T}\right]$

$\psi \quad$ : dimensionless entropy generation $\rho \quad:$ fluid density $\left[\mathrm{kg} / \mathrm{m}^{3}\right]$

$\mu \quad$ : absolute viscosity $[\mathrm{kg} / \mathrm{m} \cdot \mathrm{s}]$

$\beta \quad$ : aspect ratio

$\begin{array}{ll}\text { Subscripts } \\ \text { gen } & \text { : generation } \\ \mathrm{i} & \text { : inlet } \\ \text { o } & \text { : outlet } \\ \mathrm{w} & \text { : wall }\end{array}$

\section{References}

1. Bejan, A., Int. J. Heat Transfer, 99, 374-380(1977).

2. Sahin, A. Z., Int. J. Heat Mass Transfer, 42, 1-11(2005).

3. Ou, J. W. and Cheng, K. C., Am Soc Mech Eng Pap, 74, HT50(1974).

4. Nag, P. K. and Mukherjee, P., Int. J. Heat Mass Transfer, 30, 401-405(1987).

5. Shah, R. K. and London, A. L., Laminar Flow Forced Convection in Ducts, Academic Press (1978).

6. Ozotop, H. F., Int. J. Heat and Mass Transfer, 32, 266-274(2005).

7. Falahat, A. R., Int. J. Elixir Mech. Eng., 42, 6135-6138(2012).

8. Jankowski, T. D., Int. J. Heat and Mass Transfer, 52, 3439-3445 (2009).

9. Jarungthammachote, S. P., Int. J. Energy, 35, 5374-5379(2010).

10. Vandadi, V. and Aghanajafi, C., Journal of Mechanics, 28(1), $\operatorname{March}(2012)$.

11. Aghanajafi, C. and Mansourizadeh, M., J. Fusion Energy, 26, 299-305(2007).

12. Langeroudi, H. G. and Aghanajafi, C., J. Fusion Energy, 25, No. $3 / 4(2006)$.

13. Langeroudi, H. G. and Aghanajafi, C. J. Fusion Energy, 25, No. $3 / 4(2006)$

14. Satapathy, A. K., J Energy, 34, 1122e6(2009).

15. Hong, S. W. and Bergles, A. E., Int. J. Heat Mass Transfer, 19, 123(1976).

16. Haddad, O. M., Alkam, M. K. and Khasawneh, M. T., Int. J. Energy, 29, 35-55(2004). 